\title{
Laboratory studies of the influence of the working position of the passenger vehicle air suspension on the vibration comfort of children transported in the child restraint system
}

https://doi.org/10.1515/eng-2021-0050

Received Sep 16, 2020; accepted Jan 03, 2021

Abstract: The article presents the results of laboratory tests on the influence of the choice of the vehicle suspension position and the method of mounting child seats on the vibration comfort of children transported in them. Two child seats were used in the work. The B seat was attached to the vehicle with the ISOfix system, while the A seat was attached in the classic way (with seat belts). During the tests, the values of vertical vibrations were recorded on the seats of child seats, the rear seat of the vehicle and on the basis of ISOfix. The analyzed systems, depending on the method of mounting a child seat, may be characterized by two different vibration transmission chains. They depend on the method of fixing the child seat (the classic way of fixing the seat and the ISOFIX system). The article presents the results of empirical tests carried out at the EUSAMA SA.640 stand, which in these tests acted as a vibration generator with a frequency of 0 to $25 \mathrm{~Hz}$. The analysis of the obtained results confirmed the observations published in previous articles about the negative impact of the use of the ISOfix base on the vibrational comfort of children.

Keywords: child restraint system, comfort, vertical vibration

\section{Introduction}

In Poland, according to the Road Traffic Act, children under $150 \mathrm{~cm}$ tall may only be transported in a vehicle in a safety seat or other restraint [1]. This obligation applies to traveling in vehicles of categories M1, N1, N2 and N3,

\footnotetext{
^Corresponding Author: Emilia M. Szumska: Kielce University of Technology, Kielce, Poland; Email: eszumska@tu.kielce.pl Damian Frej, Andrzej Zuska: Kielce University of Technology, Kielce, Poland
}

¿ Open Access. (c) 2021 D. Frej et al., published by De Gruyter. (Cc) BY License with the exception of a situation where a child of at least $135 \mathrm{~cm}$ cannot travel in a child seat due to its mass and height. According to the European safety certificate ECE R44-04, the child seat must be adapted to both the height and mass of the child. This seat should comply with the requirements set out in the EU regulations or the UNECE regulations concerning child restraint systems in the vehicle [1]. The minimum requirement for the seats to be used is to be approved in accordance with the aforementioned ECE R44 / 04 certificate. Additional requirements for child seats are described in Regulation No. 44 of the United Nations Economic Commission for Europe (UN / ECE) [2]. This document distinguishes five groups of vehicle seats classified according to the child's mass. The classification is presented in Table 1.

Table 1: Classification of vehicle seats according to Regulation 44 ECE / UN [2]

\begin{tabular}{cc}
\hline Group & Mass Child, kg \\
\hline 0 & $<10$ \\
$0+$ & $<13$ \\
I & od 9 do 18 \\
II & od 15 do 25 \\
III & od 22 do 36 \\
\hline
\end{tabular}

Currently, most passenger vehicles re equipped with the ISOFIX system. The technical requirements for this system are contained in the provisions of Regulations No. 14 and No. 16 of the United Nations Economic Commission for Europe [3, 4]. Each vehicle seat with the ISOFIX system should be attached with the use of specially adapted holders, and also have a Top Tether fastening or a support. Pursuant to Regulation No. 129 of the United Nations Economic Commission for Europe (the so-called i-Size), the use of ISOFIX systems is promoted. The provisions of this standard also require rearward-facing transport of children 
under 15 months of age, which provides better protection in collisions. The i-Size standard also introduces an additional classification of seats according to the child's height [5].

Many studies and studies devoted to the analysis of accidents involving children show how important it is for safety reasons to transport children in child seats [6-8]. Scientists also pay attention to choosing the right vehicle seat and properly fastening the child. The results presented in [9] show that less than half of children aged 0-3 years involved in accidents were properly fastened. Similar conclusions were presented in [10]. Much work and projects were devoted to the development of instructions and applications that help to properly install the vehicle seat in the vehicle. Examples can be found, among others in [11, 12].

Vehicle child seats are constantly being developed and improved. Manufacturers of vehicle seats and scientists are trying to increase the protection of the child while driving and ensure a comfortable journey. The study [13] investigated the relationship between the design features of the seat and the arrangement of the belt and the comfort of driving in a group of children aged 4 to 8 years. The articles analyzed the LATCH seat mounting system [14, 15]. In [16], four methods of fastening seat belts in a rearward facing seat were analyzed. Moreover, the displacement of the seat and physical injuries of the Q1 dummy as suffered during the crash tests are discussed. The article [17] presents the results of analyzes of forces acting in the belts of belts supporting a child in a safety seat. A prototype of a vehicle seat for children weighing more than $20 \mathrm{~kg}$ has been presented in [18].

Currently, a lot of research is being conducted to investigate the behavior of a child's body in a forward-facing or rear-facing seat during tests simulating a collision using dummies. The results of these studies can be found, among others in [19-21]. The results of the crash tests presented, among others in the works [22-24] showed that improper fastening of the child in the seat may cause additional injuries.

The main function of the seat is to ensure the child's safety while traveling and to reduce the effects of possible road incidents. However, the issue of comfort is also important. As the results of the research presented in [25] show, the child's organism shows different resonance frequencies than that of an adult. In the works [26, 27], indicators based on the course of acceleration as a function of time were used to assess the comfort of the child traveling in the seat. Much work and research has been devoted to examining the frequencies of vertical vibrations transmitted from the rear seat vehicle and seat to the child's body. Examples can be found, among others in the works [28-30]. The suspension of the vehicle is an important aspect in considering the issue of passenger comfort. Vibrations originating from the places of contact of the wheels with the surface are transferred to the body and are felt by the vehicle users. This is confirmed by the research results presented in the works [30-32]. Increasingly, vehicle owners decide to purchase vehicles with active, semi-active, hydropneumatic or pneumatic suspension, which significantly improve the vibration comfort of driving. The paper [33] shows a comparison of active and passive suspension. Based on the test results, it was found that the determined values of the RMS index of accelerations recorded on the seat of a vehicle equipped with active suspension were lower than in the case of a vehicle with passive suspension. The article [34] analyzes the accelerations and longitudinal displacements of selected parts of the human body. The authors concluded that better driving comfort can be obtained by using a semiactive suspension.

Currently, in terms of comfort, an important issue is the impact of vibrations on the child's body depending on the type of seat used and the child's mass. In this study, an analysis of the influence of vertical vibrations transmitted from the body on the body of a child seated in various types of vehicle seats was undertaken. Tests were carried out with different settings of the vehicle air suspension.

\section{Measurement methodology}

The experimental studies were conducted under laboratory conditions. During the tests, the wheels of the rear axle of an Audi A6 passenger vehicle equipped with air suspension were vibrated by means of measuring plates of the EUSAMA SA device. 640. The EUSAMA SA640 device is used to test shock absorbers using the EUSAMA method and is part of the Bosch Beissbarth diagnostic line. The Eusam method is based on the kinematic excitation of the road wheel to vertical vibrations with a constant amplitude in the range of 4 to $8 \mathrm{~mm}$ and a frequency varying from the initial value of about $25 \mathrm{~Hz}$ to zero. In the experimental research, the EUSAMA SA640 device acted as a vibration generator.

The main objective of the experiment was to measure and analyze the propagation of vertical vibrations in two subsystems: vehicle body - vehicle seat - child seat, which differed in the method of mounting a child seat, taking into account three different positions of the passenger vehicle suspension. The first method of fixing the seat was to use the ISOfix base, which allows for quick and stable mounting of the child seat in the vehicle without the use of standard seat belts. However, the second method of fastening a child 
seat in a passenger vehicle requires the use of standard seat belts. Two seats were used in the experiment (Figure 1):

- Seat A - Avionaut Pixel - designed for transporting children weighing up to $13 \mathrm{~kg}$ and height $45-86 \mathrm{~cm}$. The vehicle seat's own mass is $2.5 \mathrm{~kg}$. The seat is mounted directly to the rear seat of the vehicle using standard seat belts

- Seat B - Avionaut AeroFIX - is designed to transport children with a height of $67-105 \mathrm{~cm}$ and a mass of up to $17.5 \mathrm{~kg}$. The vehicle seat's own mass is $4 \mathrm{~kg}$. The seat is mounted on the rear seat of a passenger vehicle in the direction of travel using the Avionaut IQ ISOfix base. The base was connected to the vehicle's ISOFIX system.
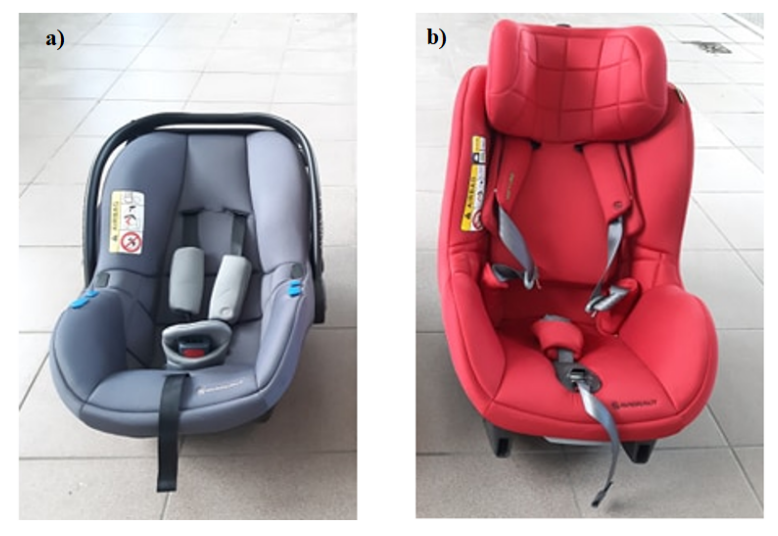

Figure 1: Tested child seats: a) seat for transporting children up to $17.5 \mathrm{~kg}$ - "A", b) seat for transporting children up to $13 \mathrm{~kg}$ - "B"

During the experimental tests, the Avionaut AeroFIX "B" seat was placed on the left side of the rear seat, which was attached to the ISOfix base (Figure 2), while the Avionaut Pixel seat was placed on the right side of the rear seat of the passenger vehicle, which was attached in a classic way, i.e. behind with the 3-point seat belts.

During the experiment, the vehicle seats were loaded with a mass imitating the mass of a child. The tests were carried out for the masses: 5, 7.5, 10, 12.5 and $15 \mathrm{~kg}$. During the tests, the vehicle was equipped with 255/35 ZR19 tires. The tires were balanced before the tests. The experimental tests were carried out for the nominal pressure in the tires and for the value of pressure reduced and increased by $15 \%$ taking into account three suspension configurations (Figure 3).

The research vehicle was a passenger vehicle with an air suspension system. In this vehicle, the user can adjust the suspension setting to the road conditions. This allows to reduce vibrations generated by uneven road surface, and

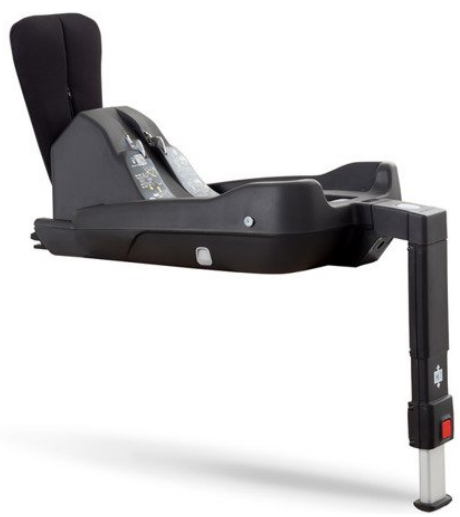

Figure 2: IQ ISOfix base for attaching child seats

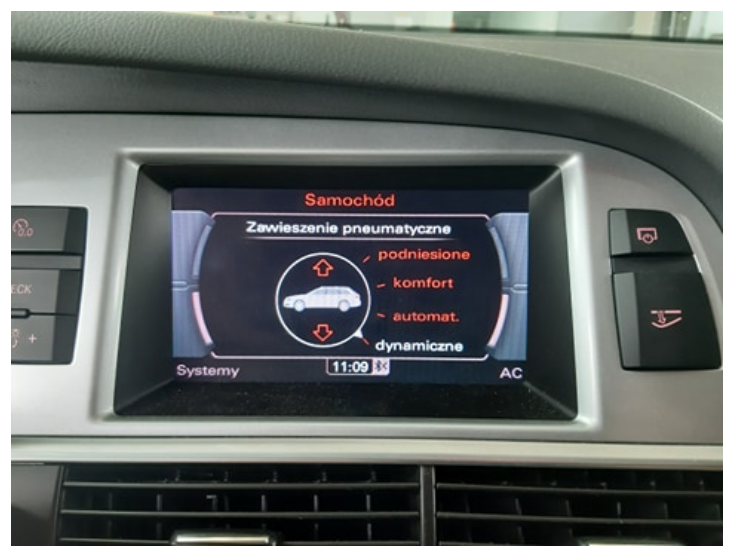

Figure 3: View of the air suspension height control panel in an Audi A6 passenger vehicle

thus improve driving comfort. The vehicle was equipped with an air suspension that can take one of three positions: dynamic, comfortable and upper. The air suspension uses air bags supplied with air by the compressor. The work of the suspension system is coordinated by an electronic module that works with the pressure distributor and valves to regulate the height of the body. During the research, acceleration was recorded using three-way acceleration sensors. Sensors using semi-flexible measuring discs are placed on: on the rear seat of the vehicle, on the seat and backrest of the child seat and in the case of the A seat based on IQ ISOfix. The research used the LMS SCADAS Recorder SCR02 digital recorder, which enables automatic operation after setting the measurement parameters. Data was recorded directly to the measuring computer.

The rms, VDV and SEAT indicators were used to analyze the truncated vibrations recorded on the seat of the child seats, the ISOfix base and the rear seat under the A seat.

The main assessment of the influence of vibrations on the vibration comfort while driving is the rms value of accelerations acting in the vertical direction (1). For accelerations 
a $(t)$ registered as the occurring stationary realization of the rms stochastic process, it is most often an indicator of the vibration comfort assessment.

$$
\text { r.m.s }=\left[\frac{1}{T} \int_{0}^{T} a^{2}(t) d t\right]^{\frac{1}{2}}
$$

where:

$a(t)$ - vertical acceleration value $\mathrm{m} / \mathrm{s}^{2}$ recorded as a function of time $t$

$T$ - segment of the measurement duration, $\mathrm{p}$.

The VDV (Vibration Dose Value) indicator was developed for vibration analysis of the whole human body. The rms and VDS values are not correlated with each other, because they accentuate the measured acceleration amplitudes in different ways. Both indicators do not estimate the impact of momentary shocks.

$$
V D V=\left[\int_{0}^{T} a^{4}(t) d t\right]^{\frac{1}{4}}
$$

where:

$a(t)$ - the frequency weighted acceleration as a function of in time, $\mathrm{m} / \mathrm{s}^{2}$

$T$ - is the duration of measurement in (s).

Using the accelerations recorded in selected points of the tested subsystem, the SEAT index was determined. This index allows to assess the degree of damping of vibrations transmitted to the seat $[5,18]$. This demonstrates the ability of the seat to damp vibrations in the vehicle in such a way as to protect the driver and passengers from excessive vibration. The SEAT value (3) is used to describe the vibration isolation of the vehicle seat [27].

$$
S E A T=\frac{V \cdot D \cdot V_{F}}{V \cdot D \cdot V_{P}}
$$

where:

V.D. $V_{F}$ - Vibration Dose Value determined for the vehicle seat

V.D. $V_{P}$ - Vibration Dose Value determined for the surface to which the vehicle seat is attached

\section{Data analysis}

The results of the measurements were used to determine the time courses of truncated accelerations. Examples of vertical vibrations recorded on the seat of the tested seats are presented in Figures 4 to 11. When comparing the courses of vertical vibration acceleration for the two tested seats,

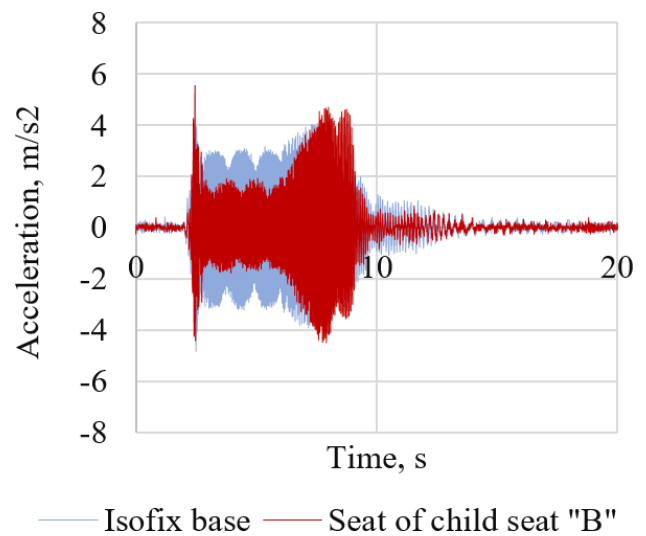

Figure 4: Vertical accelerations recorded on the seat B and ISOfix base (suspension in a dynamic position, the seat is loaded with a mass of $5 \mathrm{~kg}$ )

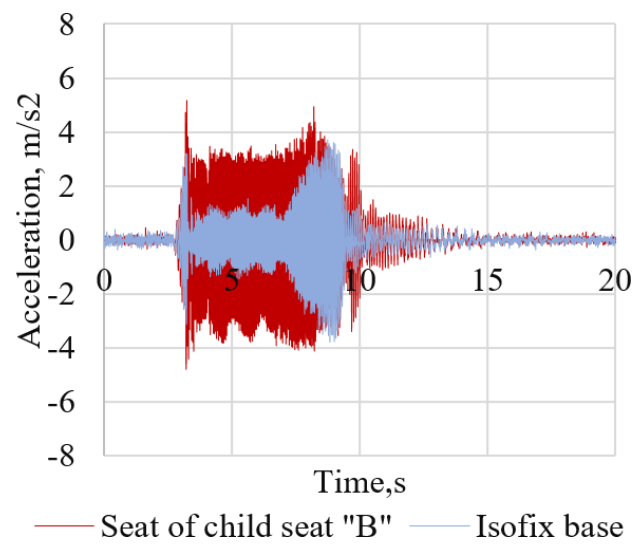

Figure 5: Vertical accelerations recorded on the seat B and ISOfix base (suspension in a raised position, the seat is loaded with a mass of $5 \mathrm{~kg}$ )

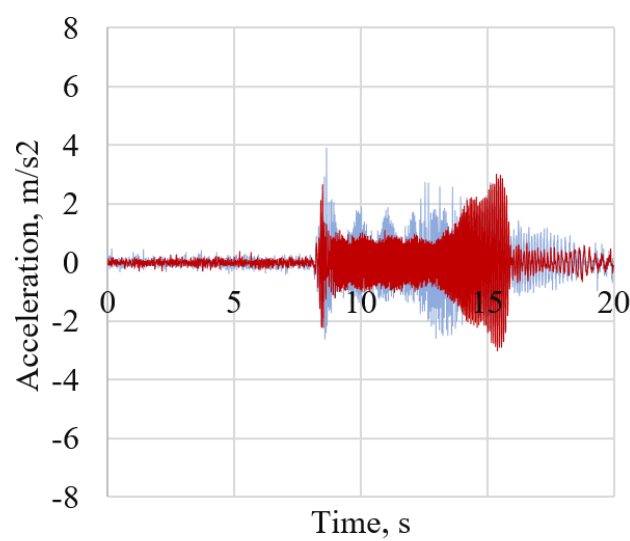

Isofix base —-Seat of child seat "B"

Figure 6: Vertical accelerations recorded on the seat B and ISOfix base (suspension in a dynamic position, the seat is loaded with a mass of $15 \mathrm{~kg}$ ) 


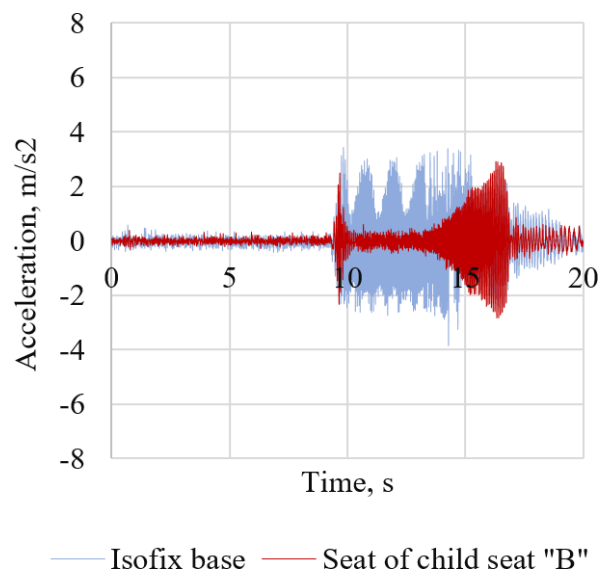

Figure 7: Vertical accelerations recorded on the seat B and ISOfix base (suspension in a raised position, the seat is loaded with a mass of $15 \mathrm{~kg}$ )

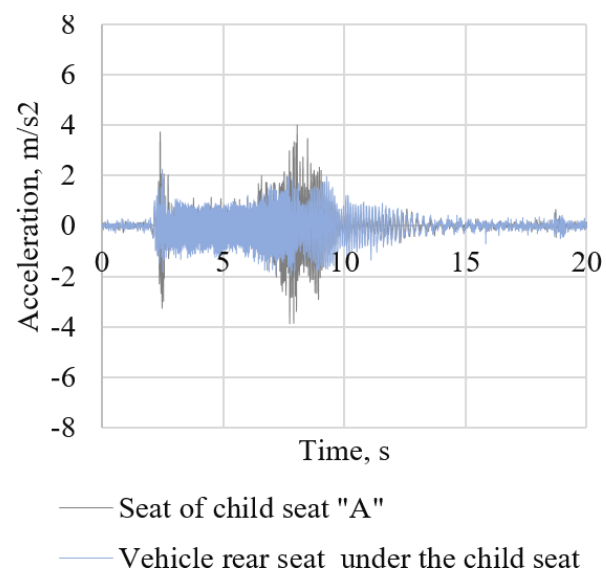

Figure 8: Vertical accelerations recorded on the seat A and ISOfix base (suspension in a dynamic position, the seat is loaded with a mass of $5 \mathrm{~kg}$



Figure 9: Vertical accelerations recorded on the seat $A$ and ISOfix base (suspension in a raised position, the seat is loaded with a mass of $5 \mathrm{~kg}$ )

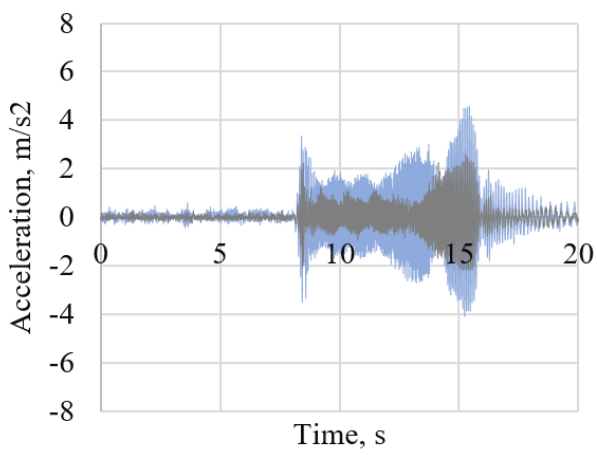

Vehicle rear seat under the child seat

- Seat of child seat "A"

Figure 10: Vertical accelerations recorded on the seat $A$ and ISOfix base (suspension in a dynamic position, the seat is loaded with a mass of $15 \mathrm{~kg}$ )

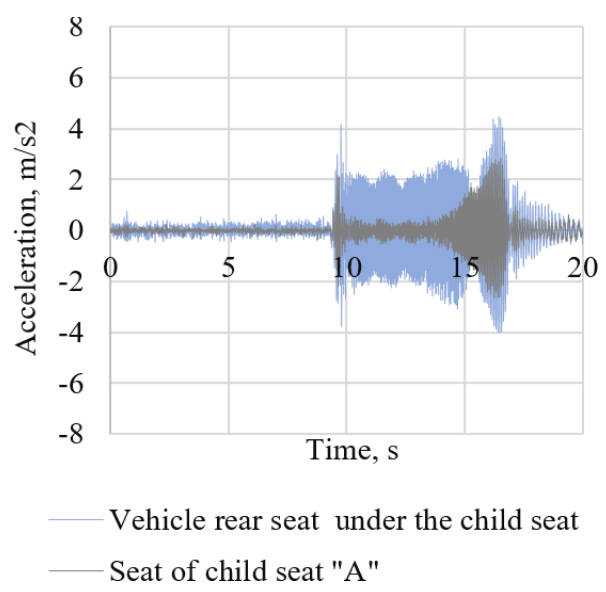

Figure 11: Vertical accelerations recorded on the seat $A$ and ISOfix base (suspension in a raised position, the seat is loaded with a mass of $15 \mathrm{~kg}$ )

it should be noted that higher acceleration values were recorded on the seat of the vehicle seat. red $\mathrm{B}$. In addition, the vertical accelerations recorded from the ISOfix database were greater than the vertical accelerations recorded on the rear seat of the test vehicle. The greatest difference in the acceleration of vertical vibrations recorded on the seat of child seats occurs when the seats are loaded with a mass of $5 \mathrm{~kg}$ and when the Audi A6 suspension is in the raised position. The smallest difference in the acceleration of vertical vibrations recorded on the seats of child seats occurs when the suspension is set in a dynamic position and the seat is loaded with a mass of $15 \mathrm{~kg}$.

Above, you should compile next to each other graphs of the time courses of vertical accelerations for different (preferably extremely different) suspension work positions but for identical loads. This time, the differences in the 
acceleration values resulting from the position in which the suspension works should be emphasized in the paper.

The rms, VDV and SEAT indicators were used to analyze the propagation of vibrations on the seats of child seats, the rear seat and the ISOfix base. The values of the rms index of accelerations recorded on the seats of the tested child seats are summarized in Table 2. The highest values are marked in red, and the lowest in green. The highest rms values of $2.61 \mathrm{~m} / \mathrm{s}^{2}$ for seat $A$ and $3.053 \mathrm{~m} / \mathrm{s}^{2}$ for seat $B$ were recorded when the vehicle was suspended in the

Table 2: Summary of RMS values for the tested child safety seats

\begin{tabular}{|c|c|c|c|c|}
\hline & \multirow{4}{*}{$\begin{array}{c}\text { Mass } \\
\text { child, } \\
\text { kg }\end{array}$} & \multirow[t]{4}{*}{ Tire pressure } & \multirow{2}{*}{\multicolumn{2}{|c|}{$\begin{array}{l}\text { Child seat } A \quad \text { Child seat } \mathrm{B} \\
\text { Location of the acceleration sensor }\end{array}$}} \\
\hline & & & & \\
\hline & & & Seat of & Seat of \\
\hline & & & Child seat & Child seat \\
\hline \multirow{15}{*}{ 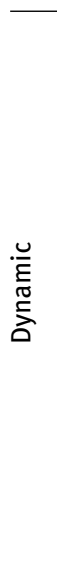 } & & $85 \%$ of nominal pressure & 1.278 & 2.388 \\
\hline & 5 & Nominal pressure & 1.307 & 2.490 \\
\hline & & $115 \%$ of nominal pressure & 2.524 & 2.872 \\
\hline & & $85 \%$ of nominal pressure & 1.225 & 2.122 \\
\hline & 7,5 & Nominal pressure & 1.319 & 2.201 \\
\hline & & $115 \%$ of nominal pressure & 1.584 & 2.260 \\
\hline & & $85 \%$ of nominal pressure & 1.572 & 1.891 \\
\hline & 10 & Nominal pressure & 1.606 & 1.935 \\
\hline & & $115 \%$ of nominal pressure & 1.620 & 1.934 \\
\hline & & $85 \%$ of nominal pressure & 1.107 & 1.324 \\
\hline & 12,5 & Nominal pressure & 1.117 & 1.358 \\
\hline & & $115 \%$ of nominal pressure & 1.076 & 1.296 \\
\hline & & $85 \%$ of nominal pressure & 1.066 & 1.306 \\
\hline & 15 & Nominal pressure & 1.089 & 1.341 \\
\hline & & $115 \%$ of nominal pressure & 1.016 & 1.236 \\
\hline \multirow{15}{*}{ 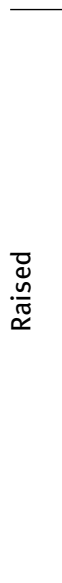 } & & $85 \%$ of nominal pressure & 1.149 & 1.971 \\
\hline & 5 & Nominal pressure & 2.610 & 3.053 \\
\hline & & $115 \%$ of nominal pressure & 2.578 & 2.848 \\
\hline & & $85 \%$ of nominal pressure & 1.292 & 2.112 \\
\hline & 7,5 & Nominal pressure & 1.356 & 2.118 \\
\hline & & $115 \%$ of nominal pressure & 2.051 & 2.459 \\
\hline & & $85 \%$ of nominal pressure & 1.308 & 1.696 \\
\hline & 10 & Nominal pressure & 1.521 & 1.924 \\
\hline & & $115 \%$ of nominal pressure & 1.619 & 2.014 \\
\hline & & $85 \%$ of nominal pressure & 0.928 & 1.000 \\
\hline & 12,5 & Nominal pressure & 0.972 & 1.125 \\
\hline & & $115 \%$ of nominal pressure & 0.988 & 1.123 \\
\hline & & $85 \%$ of nominal pressure & 0.793 & 0.921 \\
\hline & 15 & Nominal pressure & 1.034 & 1.182 \\
\hline & & $115 \%$ of nominal pressure & 1.074 & 1.214 \\
\hline \multirow{15}{*}{ 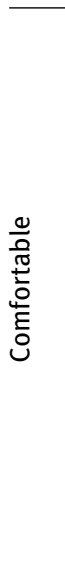 } & & $85 \%$ of nominal pressure & 2.481 & 1.122 \\
\hline & 5 & Nominal pressure & 2.509 & 1.262 \\
\hline & & $115 \%$ of nominal pressure & 1.895 & 1.297 \\
\hline & & $85 \%$ of nominal pressure & 1.378 & 1.221 \\
\hline & 7,5 & Nominal pressure & 1.399 & 1.258 \\
\hline & & $115 \%$ of nominal pressure & 1.372 & 1.184 \\
\hline & & $85 \%$ of nominal pressure & 1.647 & 0.978 \\
\hline & 10 & Nominal pressure & 1.852 & 1.051 \\
\hline & & $115 \%$ of nominal pressure & 1.897 & 1.084 \\
\hline & & $85 \%$ of nominal pressure & 1.122 & 0.997 \\
\hline & 12,5 & Nominal pressure & 1.262 & 1.144 \\
\hline & & $115 \%$ of nominal pressure & 1.297 & 1.184 \\
\hline & & $85 \%$ of nominal pressure & 1.221 & 1.015 \\
\hline & 15 & Nominal pressure & 1.258 & 1.027 \\
\hline & & $115 \%$ of nominal pressure & 1.184 & 0.998 \\
\hline
\end{tabular}


Table 3: Results of the VDV and SEAT indicators

\begin{tabular}{|c|c|c|c|c|c|c|}
\hline \multirow{4}{*}{$\begin{array}{l}\bar{\Sigma} \\
\frac{0}{n} \\
\bar{v} \\
\frac{0}{n} \\
\tilde{y}\end{array}$} & \multirow{4}{*}{$\begin{array}{c}\text { Mass } \\
\text { child, } \\
\text { kg }\end{array}$} & \multirow[t]{4}{*}{ Tire pressure } & \multirow{2}{*}{\multicolumn{4}{|c|}{$\begin{array}{l}\text { Child seat A Child seat } \\
\text { Location of the acceleration sensor }\end{array}$}} \\
\hline & & & & & & \\
\hline & & & \multicolumn{2}{|c|}{ Seat of Child seat } & \multicolumn{2}{|c|}{ Seat of Child seat } \\
\hline & & & VDV & SEAT & VDV & SEAT \\
\hline \multirow{15}{*}{  } & & $85 \%$ of nominal pressure & 3.812 & 2.259 & 1.883 & 0.843 \\
\hline & 5 & Nominal pressure & 3.873 & 2.246 & 2.196 & 1.004 \\
\hline & & $115 \%$ of nominal pressure & 3.326 & 2.190 & 2.264 & 0.483 \\
\hline & & $85 \%$ of nominal pressure & 2.405 & 1.388 & 3.977 & 1.012 \\
\hline & 7,5 & Nominal pressure & 2.490 & 1.425 & 4.229 & 1.030 \\
\hline & & $115 \%$ of nominal pressure & 6.071 & 3.727 & 4.505 & 1.265 \\
\hline & & $85 \%$ of nominal pressure & 2.166 & 1.214 & 3.413 & 0.914 \\
\hline & 10 & Nominal pressure & 4.749 & 3.608 & 4.629 & 1.538 \\
\hline & & $115 \%$ of nominal pressure & 5.457 & 3.621 & 4.473 & 1.368 \\
\hline & & $85 \%$ of nominal pressure & 2.532 & 1.608 & 2.101 & 1.027 \\
\hline & 12,5 & Nominal pressure & 2.594 & 1.629 & 2.173 & 0.947 \\
\hline & & $115 \%$ of nominal pressure & 2.507 & 1.662 & 2.062 & 0.725 \\
\hline & & $85 \%$ of nominal pressure & 1.966 & 1.210 & 3.265 & 1.241 \\
\hline & 15 & Nominal pressure & 2.206 & 1.314 & 3.394 & 1.242 \\
\hline & & $115 \%$ of nominal pressure & 2.930 & 1.761 & 3.505 & 1.270 \\
\hline \multirow{15}{*}{  } & & $85 \%$ of nominal pressure & 2.253 & 1.731 & 3.561 & 1.717 \\
\hline & 5 & Nominal pressure & 2.386 & 1.667 & 3.456 & 1.459 \\
\hline & & $115 \%$ of nominal pressure & 3.737 & 2.680 & 3.865 & 1.612 \\
\hline & & $85 \%$ of nominal pressure & 2.626 & 1.111 & 3.525 & 2.071 \\
\hline & 7,5 & Nominal pressure & 3.124 & 1.087 & 3.809 & 2.020 \\
\hline & & $115 \%$ of nominal pressure & 3.162 & 1.073 & 3.877 & 1.872 \\
\hline & & $85 \%$ of nominal pressure & 2.877 & 0.735 & 3.098 & 1.556 \\
\hline & 10 & Nominal pressure & 2.978 & 0.760 & 3.165 & 1.584 \\
\hline & & $115 \%$ of nominal pressure & 2.997 & 0.761 & 3.134 & 1.600 \\
\hline & & $85 \%$ of nominal pressure & 2.408 & 0.727 & 2.729 & 1.528 \\
\hline & 12,5 & Nominal pressure & 2.598 & 0.782 & 3.064 & 1.498 \\
\hline & & $115 \%$ of nominal pressure & 2.937 & 0.766 & 3.239 & 1.628 \\
\hline & & $85 \%$ of nominal pressure & 1.883 & 1.082 & 3.176 & 1.395 \\
\hline & 15 & Nominal pressure & 2.196 & 1.119 & 3.666 & 1.558 \\
\hline & & $115 \%$ of nominal pressure & 2.264 & 1.117 & 3.789 & 1.452 \\
\hline \multirow{15}{*}{$\begin{array}{l}\frac{0}{0} \\
\frac{0}{0} \\
\frac{0}{0} \\
\frac{0}{0} \\
0 \\
0\end{array}$} & & $85 \%$ of nominal pressure & 1.984 & 0.548 & 2.240 & 0.988 \\
\hline & 5 & Nominal pressure & 1.986 & 0.548 & 2.259 & 0.917 \\
\hline & & $115 \%$ of nominal pressure & 1.981 & 0.547 & 2.228 & 0.684 \\
\hline & & $85 \%$ of nominal pressure & 1.790 & 0.534 & 1.819 & 0.743 \\
\hline & 7,5 & Nominal pressure & 1.982 & 0.428 & 2.060 & 0.330 \\
\hline & & $115 \%$ of nominal pressure & 1.930 & 0.506 & 2.013 & 0.599 \\
\hline & & $85 \%$ of nominal pressure & 2.101 & 1.166 & 3.342 & 1.599 \\
\hline & 10 & Nominal pressure & 2.173 & 1.166 & 3.389 & 1.254 \\
\hline & & $115 \%$ of nominal pressure & 2.062 & 1.131 & 3.157 & 0.993 \\
\hline & & $85 \%$ of nominal pressure & 1.920 & 0.564 & 2.300 & 1.198 \\
\hline & 12,5 & Nominal pressure & 1.943 & 0.557 & 2.363 & 0.897 \\
\hline & & $115 \%$ of nominal pressure & 1.817 & 0.526 & 2.115 & 0.682 \\
\hline & & $85 \%$ of nominal pressure & 1.543 & 0.528 & 1.683 & 0.750 \\
\hline & 15 & Nominal pressure & 2.042 & 0.578 & 2.255 & 0.680 \\
\hline & & $115 \%$ of nominal pressure & 2.093 & 0.575 & 2.302 & 0.551 \\
\hline
\end{tabular}

raised position and the seats were loaded with a mass of $5 \mathrm{~kg}$. These values prove that for children weighing $5 \mathrm{~kg}$, setting the suspension in the raised position is unfavorable.
Table 3 presents the results of the VDV and SEAT indicators. The highest value of the VDV index was $6.071 \mathrm{~m} / \mathrm{s}^{1.75}$ for the A car seat with a mass of $7.5 \mathrm{~kg}$. On the other hand, the highest value of the SEAT indicator is 3.727 , also for the seat A with a load of $7.5 \mathrm{~kg}$. 
The maximum values of the indexes were recorded during the dynamic suspension adjustment of the passenger car. On the other hand, the smallest value when adjusting the suspension comfortably. It should be noted that the lowest value of the VDV index is $1.543 \mathrm{~m} / \mathrm{s}^{1.75}$ for the seat $\mathrm{A}$, and was recorded for a mass of $15 \mathrm{~kg}$. On the other hand, the lowest value of the SEAT indicator is 0.330 for seat $\mathrm{B}$ with a mass of $7.5 \mathrm{~kg}$

Assuming that the pressure in the tires will be maintained at the nominal level, for children weighing $5 \mathrm{~kg}$ in the A vehicle seat, the most advantageous in terms of vibration comfort turned out to be the dynamic position of the suspension, while for children transported in the B seat, the most advantageous position was to set the suspension to the comfort position. The most unfavorable suspension setting from the point of view of vibration comfort for children weighing $5 \mathrm{~kg}$ turns out to be the best for children weighing $15 \mathrm{~kg}$, provided that the pressure in the tires is reduced by $15 \%$. With the nominal air pressure in the tires, the most advantageous for children weighing $15 \mathrm{~kg}$ in the $\mathrm{B}$ seat (fixed in the classic way) is to set the suspension to the comfort position, while for children of the same mass but transported in the A seat (fastened with the ISOfix system), the best is to shift the suspension into dynamic position.

The ISO 2631-1 standard, in addition to the effective rms values, also provides for the use of the VDV index to assess the impact of vertical vibrations on a person in a sitting position [35]. The values of this index for all (forty) measurement tests are presented in Figures 12-16. They illustrate the influence of the suspension position and air pressure in the tires of the test vehicle on the values of the VDV index of accelerations recorded on the seats of the tested child seats. The influence of the operating position of the suspension and air pressure in the tires on the VDV index values was analyzed for four different load variants of the tested seats.

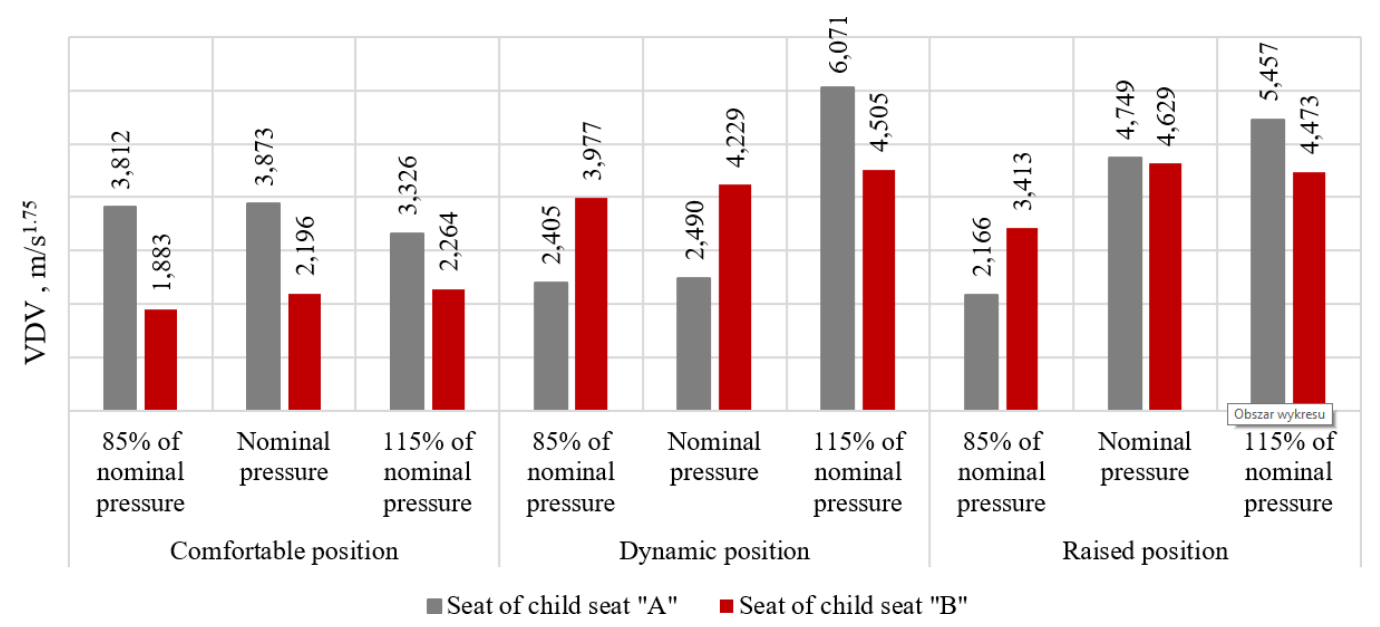

Figure 12: VDV index for the tested seats, loaded with a mass of $5 \mathrm{~kg}$ during the tests

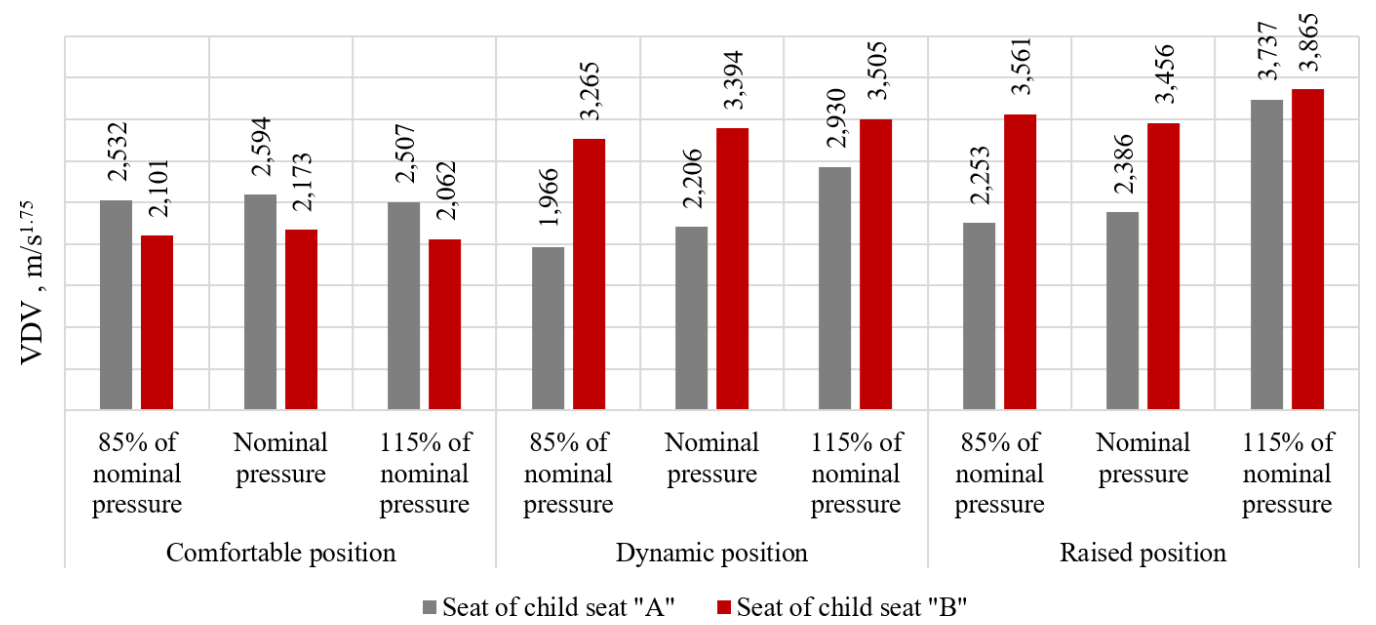

Figure 13: VDV index for the tested seats, loaded with a mass of $7.5 \mathrm{~kg}$ during the tests 


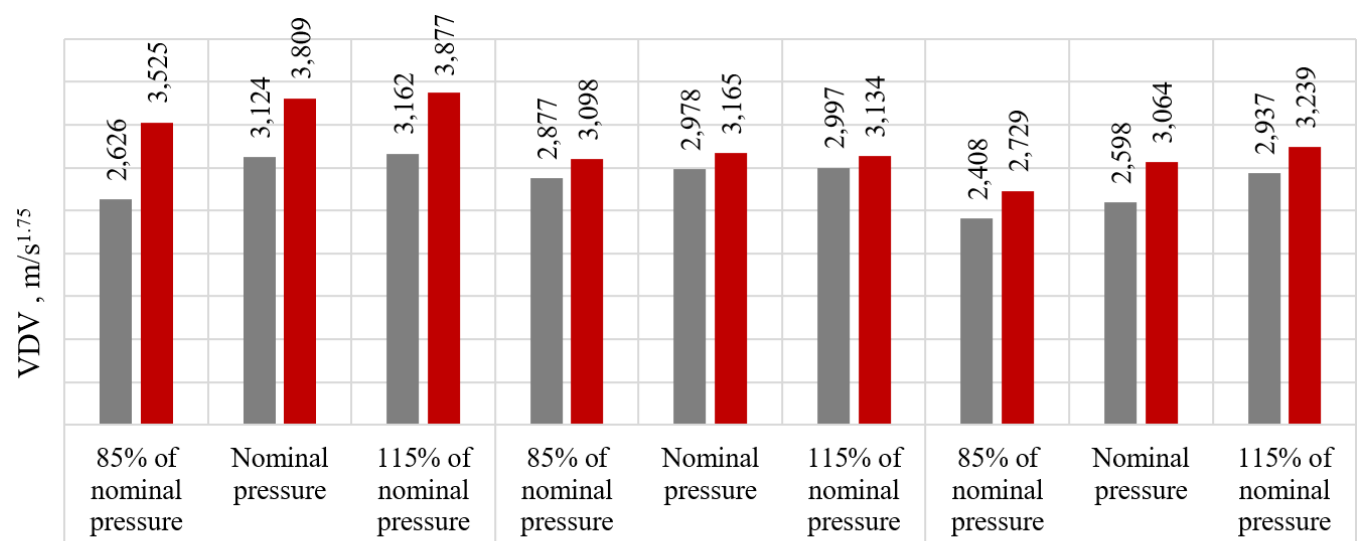

Comfortable position

Dynamic position

Raised position

- Seat of child seat "A" — Seat of child seat "B"

Figure 14: VDV index for the tested seats, loaded with a mass of $10 \mathrm{~kg}$ during the tests

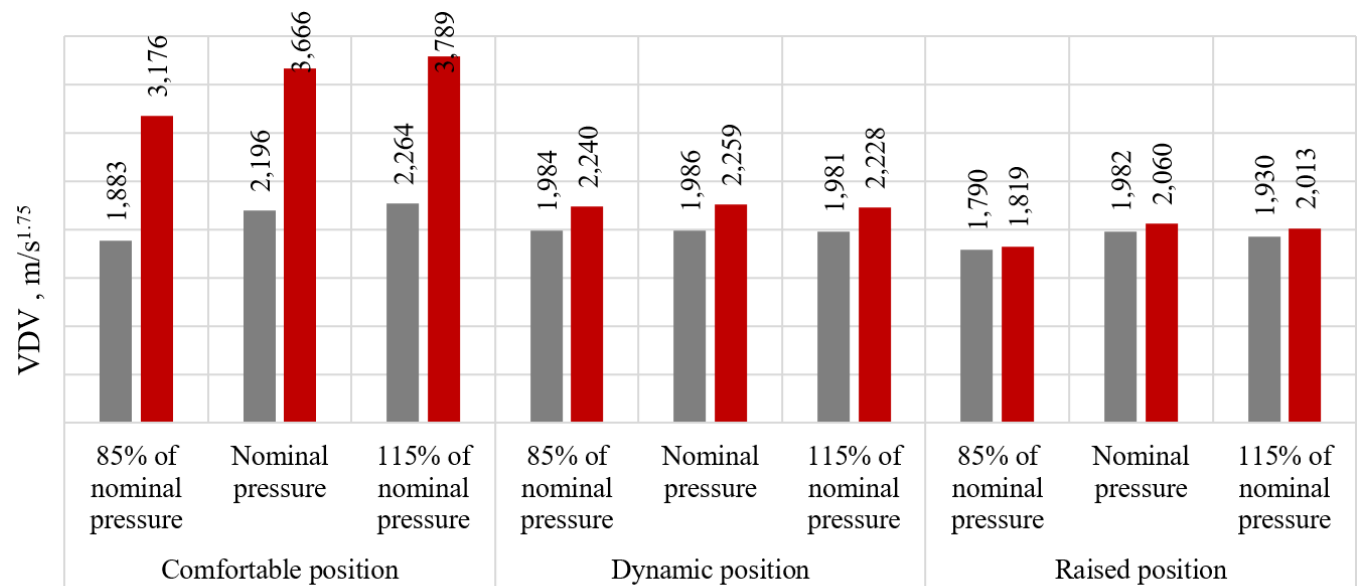

- Seat of child seat "A" — Seat of child seat "B"

Figure 15: VDV index for the tested seats, which were loaded with a mass of $12.5 \mathrm{~kg}$ during the tests

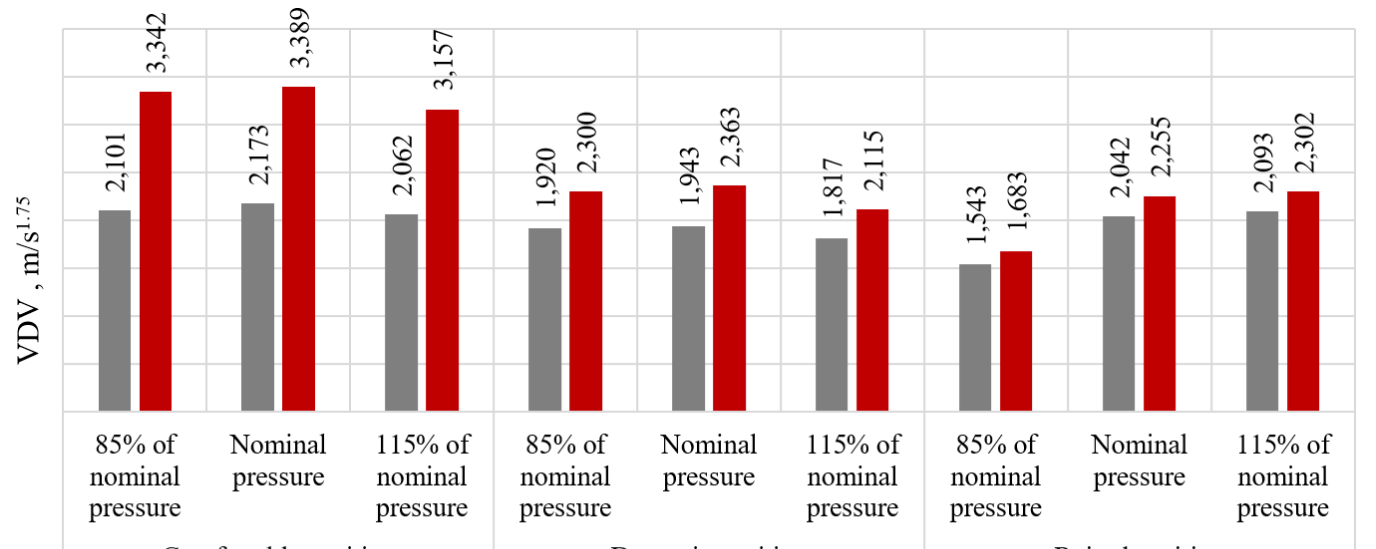

Comfortable position

Dynamic position

Raised position

— Seat of child seat "A" — Seat of child seat "B"

Figure 16: VDV index for vehicle seats that were loaded with a mass of $15 \mathrm{~kg}$ during the tests 


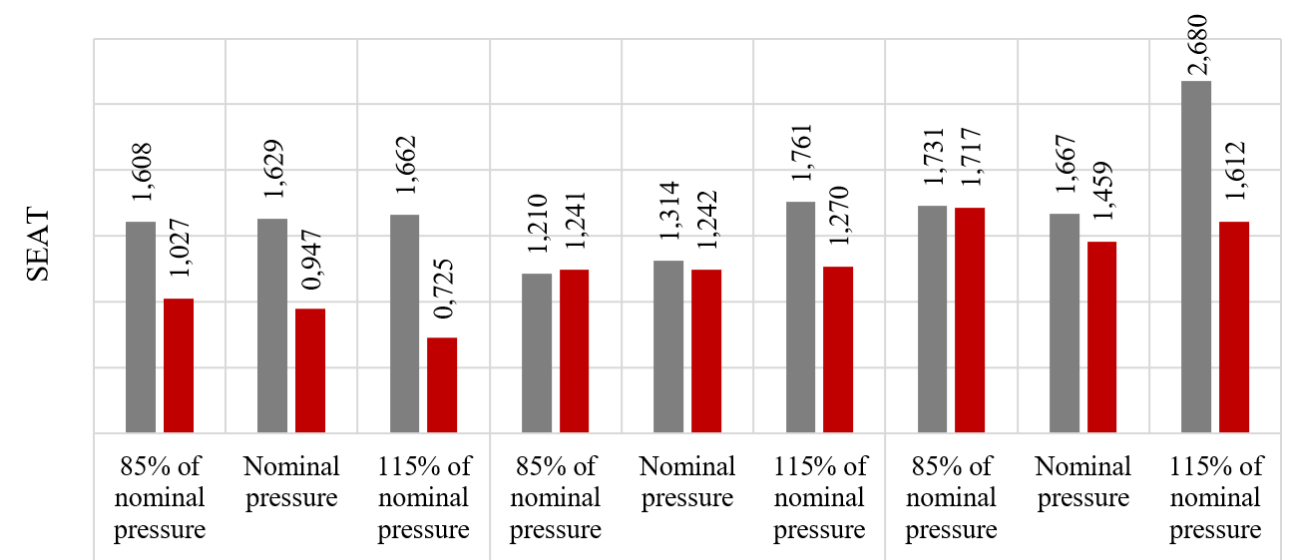

Comfortable position

Dynamic position

Raised position

- Seat of child seat "A" $\quad$ - Seat of child seat "B"

Figure 17: SEAT indicator on the seat of the tested child seats with a load of $7.5 \mathrm{~kg}$

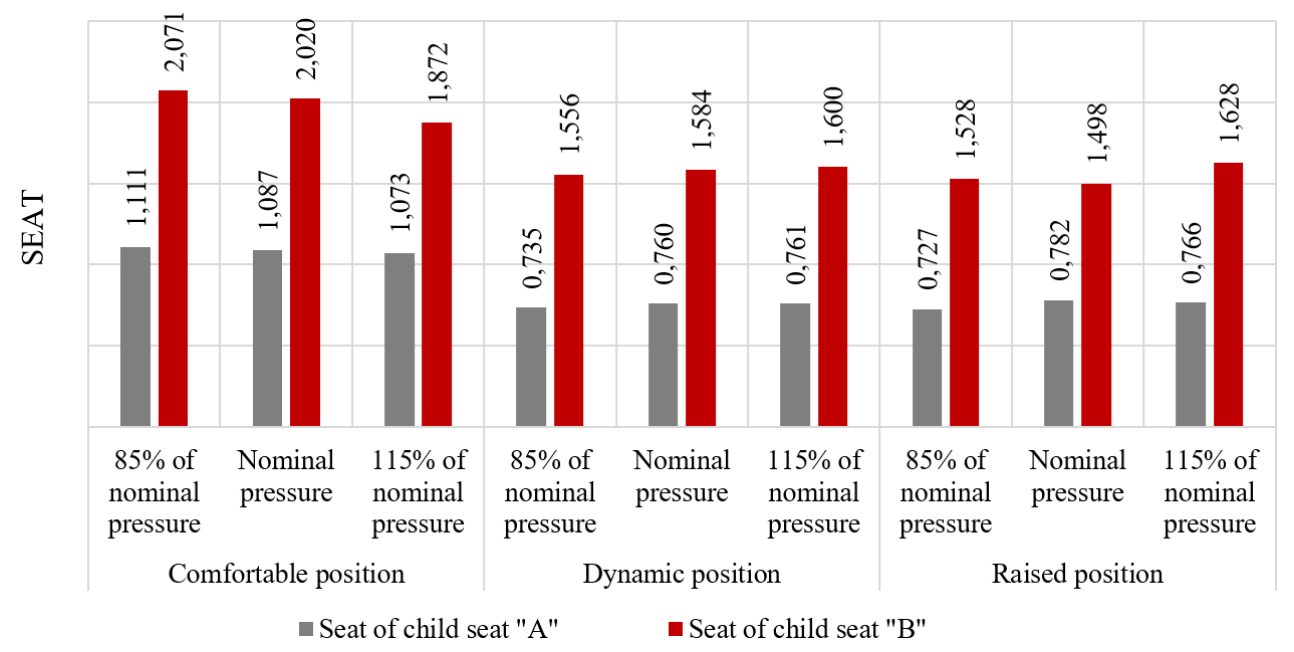

Figure 18: SEAT indicator on the seat of the tested child seats with a load of $10 \mathrm{~kg}$

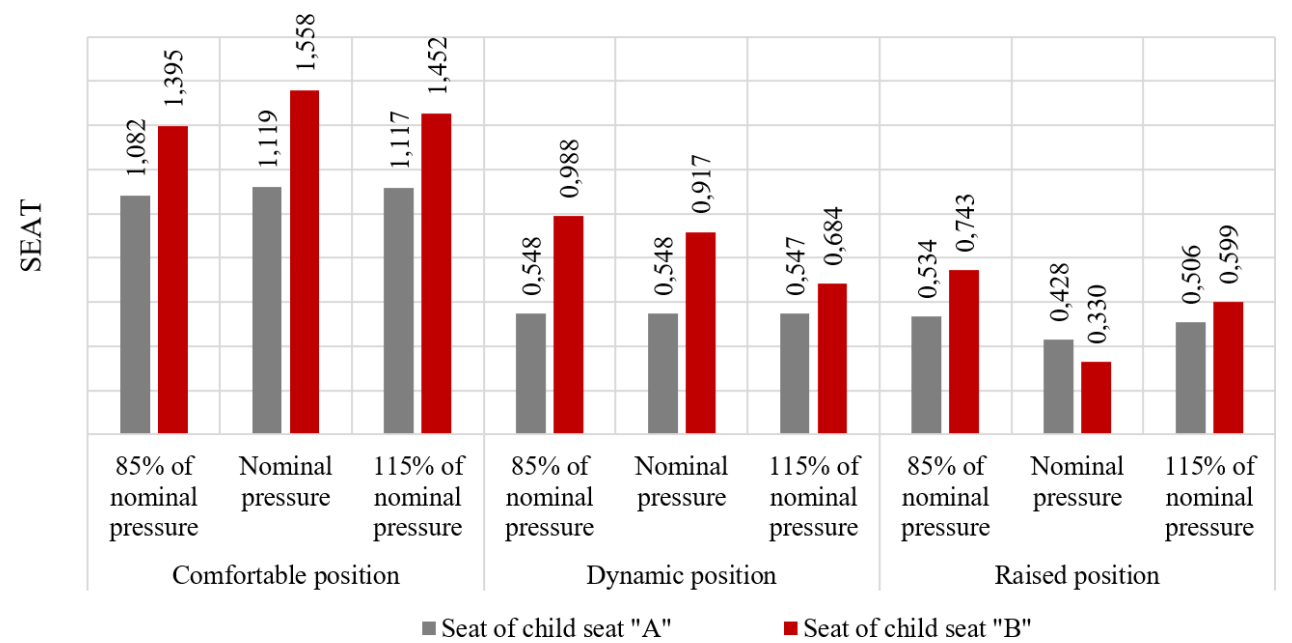

Figure 19: SEAT indicator on the seat of the tested child seats with a mass of $12.5 \mathrm{~kg}$ 


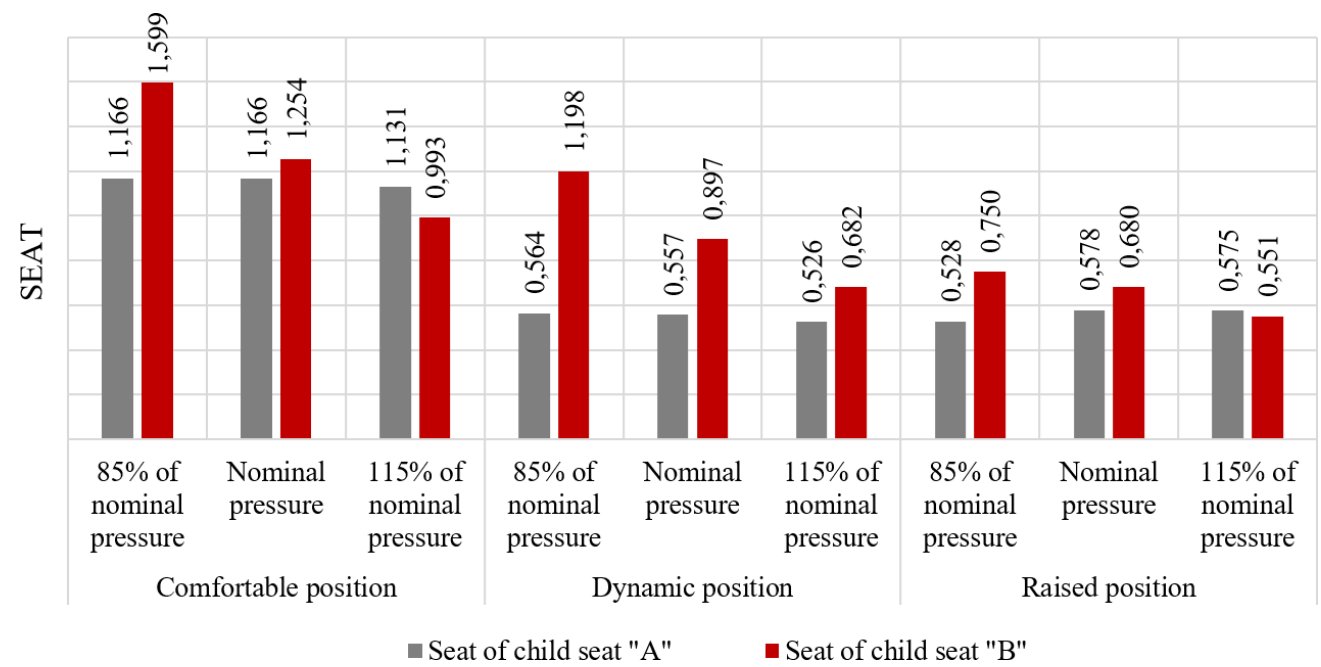

Figure 20: SEAT indicator on the seat of the tested child seats with a mass of $15 \mathrm{~kg}$

The analyzes of the VDV index show that when the B (red) seat was loaded with a mass less than or equal to $7.5 \mathrm{~kg}$, it is more advantageous in terms of vibration comfort to set the vehicles suspension to the comfort position. For other load variants, it is more advantageous to set the suspension in a raised or dynamic position in terms of vibration comfort. The situation is completely different when we analyze the values of the VDV index for the A (gray) seat. This time, in four out of five cases where the seat is loaded $(5 \mathrm{~kg}$, $7.5 \mathrm{~kg}, 10 \mathrm{~kg}, 15 \mathrm{~kg}$ ) at nominal air pressure in the tires, it is more advantageous in terms of vibration comfort to set the suspension in a dynamic or raised position. In the case where the A (gray) seat is loaded with a mass of $5 \mathrm{~kg}$, the best comfort in terms of comfort is setting the suspension in the raised position, assuming that the air pressure in the wheels will be reduced by $15 \%$ compared to the nominal pressure. In most cases, as the pressure in the vehicle wheels increases, the VDV values also increase.

Figures 17-20 show the values of the SEAT indicator for seats with a mass of $7.5 \mathrm{~kg}, 10 \mathrm{~kg}, 12.5 \mathrm{~kg}$ and $15 \mathrm{~kg}$. The analysis shows that in the vast majority of cases, the values of this index determined for the $B$ (red) seat were higher than the values determined for the A (gray) seat. This shows that the vibrations transferred from the ISOfix base to the red seat were reduced to a greater extent than the vibrations transmitted from the rear seat cushion to the A (gray) seat, which was attached in a conventional manner. The opposite was observed in only ten out of thirty-six cases. It should be emphasized that most of these cases (nine) were reported when the vehicle seats were loaded with a mass of $7.5 \mathrm{~kg}$.

\section{Conclusions}

The subject of the research is part of the issue of the vibration comfort of children transported in child seats. The presented research is a part of a whole series of research carried out by employees of the Department of Motor Vehicles and Transport of the Kielce University of Technology. They concern the spread of vertical bastards in the following system: vehicle (vehicle floor) - vehicle seat cushion child seat. In the conducted research, it was noticed that the position of the suspension of a vehicle equipped with air suspension may have a significant impact on the transmission of vibrations from the road surface to the seat of the child seat.

The review of literature items allowed to state that child seats are the subject of many studies and analyzes in terms of the passive safety of children transported in them, while static (comfort) and vibration comfort seem to be completely overlooked. This can be proved by a very modest number of publications describing these issues. The authors of these publications (regarding the comfort of children transported in child seats) focus mainly on the place, position and method of fastening the seats.

The authors of this study decided to draw attention to two elements, overlooked by the authors of other publications, which significantly affect the assessment of the vibration comfort of children transported in child seats. These elements include: the mass of the child and the characteristics of the car suspension in which the child seats are attached.

Laboratory tests of child seats, in terms of vibration comfort, are quite troublesome to carry out because the applicable regulations exclude the possibility of children 
participating in them. Therefore, the authors plan to carry out a series of operational tests involving children of various mass and anthropometric dimensions, as permitted by the regulations. The research results obtained in this way will be used to develop a concept and build an innovative vibration reduction system that will be integrated into the child seat mounting system. In addition, it is planned to develop the currently missing criteria for assessing the vibration comfort of children transported in child seats.

The paper presents the results of empirical tests carried out at the EUSAMA SA.640 stand, which in these tests acted as a generator of vibrations with a frequency of 0 to $25 \mathrm{~Hz}$. It should be noted that the air suspension from the assembly is to improve the traction parameters of the vehicle. Such solutions are to ensure optimal reduction of vibrations coming from the road surface. Consequently, the air suspension is to improve driving comfort. The ISOfix base separates the seat from the rear seat of the vehicle. This system enables quick and stable mounting of a child seat in the vehicle. In addition, together with the seat, the ISOfix base creates a system that is subject to acceleration from the vehicles floor plate. Consequently, it contributes to the deterioration of the vibration comfort of children carried in the seat. The negative impact of separating the child seat from the rear seat of a passenger vehicle with the ISOfix base is confirmed by the r.m.s and VDV values determined for the $\mathrm{B}$ seat, which were higher than the rms values and VDV values determined for the A seat fitted in a classic way.

They found that in most of the tests conducted for the A seat, the comfort position was less favorable in terms of vibration comfort than the dynamic suspension position. In turn, for children weighing from $7.5 \mathrm{~kg}$ to $15 \mathrm{~kg}$ transported in a red seat, it is more advantageous in terms of vibration comfort to set the suspension in the comfort position. Noteworthy is the fact that it has a significant impact on the vibration comfort, the mass of the child carried in the seat and the pressure in the tires of the vehicle.

\section{References}

[1] Polish Road Traffic Act of 20 June 1997 (Ustawa z dnia 2 czerwca 1997 r. Prawo o ruchu drogowym, Dz. U. 1997 Nr 98 poz. 602), avalaible on https://isap.sejm.gov.pl/isap.nsf/downlo ad.xsp/WDU19970980602/U/D19970602Lj.pdf

[2] Regulation No 44 of the Economic Commission for Europe of the United Nations (UN/ECE) - Uniform provisions concerning the approval of restraining devices for child occupants of powerdriven vehicles ('Child Restraint Systems').

[3] Regulation No 16 of the Economic Commission for Europe of the United Nations (UN/ECE) - Uniform provisions concerning the approval of: I. safety-belts, restraint systems, child restraint systems and Isofix child restraint systems for occupants of powerdriven vehicles II. vehicles equipped with safety-belts, restraint systems, child restraint systems and Isofix child restraint systems,

[4] Regulation No 129 of the Economic Commission for Europe of the United Nations (UN/ECE) - Uniform provisions concerning the approval of enhanced Child Restraint Systems used on board of motor vehicles (ECRS)

[5] K. Omari, O. Baron-Epel, Low rates of child restraint system use in cars may be due to fatalistic beliefs and other factors, Transportation Research Part F: Traffic Psychology and Behaviour, Volume 16, January 2013, pp. 53-59,

[6] S.L. Bachman, G.A. Salzman, R.V. Burke, H. Arbogast, P. Ruiz, J. S. Upperman, Observed child restraint misuse in a large, urban community: Results from three years of inspection events, Journal of Safety Research Volume 56, February 2016, pp. 17-22.

[7] P.A. Skjerven-Martinsen, T.B. Naess, T. Hansen, A. Staff, StrayPedersen, Observational study of child restraining practice on Norwegian high-speed roads: Restraint misuse poses a major threat to child passenger safety, Accident Analysis \& Prevention, Volume 59, October 2013, pp. 479-486.

[8] G. Lee, C.N. Pope, A. Nwosu, L.B. McKenzie, M. Zhu, Child passenger fatality: Child restraint system usage and contributing factors among the youngest passengers from 2011 to 2015, Journal of Safety Research, Volume 70, September 2019, pp. 33-38,

[9] M. Roynard, P. Silverans, Y. Casteels, P. Lesire, National roadside survey of child restraint system use in Belgium, Accident Analysis \& Prevention, Volume 62, January 2014, pp. 369-376.

[10] D.C. Schwebel, M. A. Tillman, M. Crew, M. Muller, A. Johnston, Using interactive virtual presence to support accurate installation of child restraints: Efficacy and parental perceptions, Journal of Safety Research, Volume 62, September 2017, pp. 235-243.

[11] K.D. Klinich, M.A. Manary, C.A. C. Flannagan, S.M. Ebert, L.A. Malik, P.A. Green, M. P. Reed, Effects of child restraint system features on installation errors, Applied Ergonomics, Volume 45, Issue 2, Part B, March 2014, pp. 270-277.

[12] B. Albanese, K. Bohman, L. Bilston, S. Koppel, J. L. Charlton, J. Olivier, L. Keay, J. Brown, Influence of child restraint system design features on comfort, belt fit and posture, Safety Science, Volume 128, August 2020, 104707.

[13] J. B. Cicchino, J. S. Jermakian, Vehicle characteristics associated with LATCH use and correct use in real-world child restraint installations, Journal of Safety Research, Volume 53, June 2015, pp. 77-85, https://www.sciencedirect.com/science/articl e/pii/S0022437515000213

[14] J. S. Jermakian, K. D. Klinich, N. R. Orton, C. A. C. Flannagan, M. A. Manary, L. A. Malik, Prabha Narayanaswamy, Factors affecting tether use and correct use in child restraint installations, Journal of Safety Research, Volume 51, December 2014, pp. 99-108.

[15] L. Peng, Y. Han, D. Pan, K. Mizuno, Constrained Path Optimization in G0 + Group Children Restraint System Based on UN R129, Proceedings of 9th International Conference on Measuring Technology and Mechatronics Automation (ICMTMA), 14-15 January 2017, Changsha, China.

[16] A. Muszyński, P. Trzaska, J.Wicher, t. Mazurkiewicz, Analysis of the forces developing in the straps of the belts that restrain a child in a safety seat, The Archives of Automotive Engineering Archiwum Motoryzacji; 67(1), 2015, pp. 113-126. 
[17] C. Taff, M. Franco, R. Chung, S. PremDas, Adjustable booster child restraint system to enhance safety, Proceedings of IEEE 37th Annual Northeast Bioengineering Conference (NEBEC), pp. 1-3.

[18] E. Rola, D. Wdowicz, Is it safer to transport a three-year-old child in a forward-facing child restraint system or in a rear-facing one while head-on collision?, Proceedings of International Interdisciplinary PhD Workshop (IIPhDW), 9-12 May 2018, Swinoujście, Poland.

[19] Y. Han, L. Yuan Peng, D. Pan, H. Cong Tang, H. Huang, K. Mizuno, Soft Tissue Injury Risk in Chest and Abdomen of $3 Y 0$ child Based on CRS Dynamic Load, Proceedings of 10th International Conference on Measuring Technology and Mechatronics Automation (ICMTMA), 10-11 February 2018, Changsha, China.

[20] W. Kai, B. Peng, M. Weijie, Research on the Influence to Rear Child Dummy Injure of Safe Seat in Frontal Crash Test, Proceedings of Fifth International Conference on Measuring Technology and Mechatronics Automation, 16-17 January 2013, Hong Kong, China.

[21] P. Posuniak, M. Jaśkiewicz, K. Kowalski, F. Dąbrowski, Child restraint systems: Problems related to the safety of children transported in booster seats (without integral safety belts), Proceedings of XI International Science-Technical Conference Automotive Safety, 18-20 April 2018, Casta, Slovakia.

[22] Y. Han, J. Xie, K. Mizuno, H. Huang, G. Renhong, C. Anguo, Research on the Risk of Child Occupant Injury Based on Offset Impact, Proceedings of Eighth International Conference on Measuring Technology and Mechatronics Automation (ICMTMA), 11-12 March 2016, Macau, China.

[23] H. Yong, L. Xiaoping, K. Miuzno, G. Renhong, C. Anguo, Parameter Optimization of Child Restraint System Based on Orthogonal Experiment, Proceedings of Eighth International Conference on Measuring Technology and Mechatronics Automation (ICMTMA), 11-12 March 2016, Macau, China.

[24] J. Giacomin, S Gallo, In-vehicle vibration study of child safety seats, Ergonomics, 15; 46(15), 2003, pp. 1500-1512.

[25] J. Wicher, D. Więckowski, Influence of vibrations of the child seat on the comfort of child's ride in a car, Maintenance And Reliability, 4, 2010, pp. 102-110.
[26] D.P. Frej, A. Zuska, K. Cadge, Analysis of vertical vibrations affecting a child transported in a child seat during a car passing over the release speed bump, The Archives of Automotive Engineering - Archiwum Motoryzacji, 86(4), 2019, pp.111-125.

[27] S. Jin Park, S. Nam Min, M. Subramaniyam, Heeran Lee, Dong Gyun Kim, Cheol Pyo Hong, Vibration Effect Investigation in Baby Car Seats and Automobile Seats, SAE Technical Paper 2014-010462, 2014.

[28] T. Gromadowski, D. Więckowski, Analysis of vertical vibrations acting on children in child car seats, Journal of KONES Powertrain and Transport, Vol. 20, No. 1, 2013, pp. 359-366.

[29] J. Giacomin, S. Gallo, In-vehicle vibration study of child safety seats, Ergonomics, 15; 46(15), 2003, pp. 1500-1512.

[30] A. Sezgin, Yunus Z. Arslan, Analysis of the vertical vibration effects on ride comfort of vehicle driver, Journal of Vibroengineering, Vol. 14, Issue 2, 2012, pp. 559-571.

[31] M. Nagai, H. Yoshida, T. Tohtake, Y. Suzuki, Coupled vibration of passenger and lightweight car-body in consideration of humanbody biomechanics, Vehicle System Dynamics, International Journal of Vehicle Mechanics and Mobility, Volume 44, 2006, pp. 601-611.

[32] R. Burdzik, Identification of structure and directional distribution of vibration transferred to car-body from road roughness, Journal of Vibroengineering, Vol. 16, Issue 1, 2014, pp. 324-333.

[33] A. Shirahatt, P.S. Prasad, P. Panzade, M.M. Kulkarni, Optimal Design of Passenger Car Suspension for Ride and Road, Journal of the Brazilian Society of Mechanical Sciences and Engineering, vol. 30 no.1, 2008.

[34] D.V.A. Rama Sastry, K.V. Ramanaa, N. Mohan Rao, M. Phani Kumar, V.S.S. Rama Chandra Reddy, Evaluation of human exposure to vibrations using quarter car model with semi-active suspension, International Journal of Vehicle Structures and Systems, Vol. 10, Issue 4, 2018, pp. 268-272.

[35] ISO 2631-1:1997 Mechanical vibration and shock - Evaluation of human exposure to whole-body vibration - Part 1: General requirements. 